
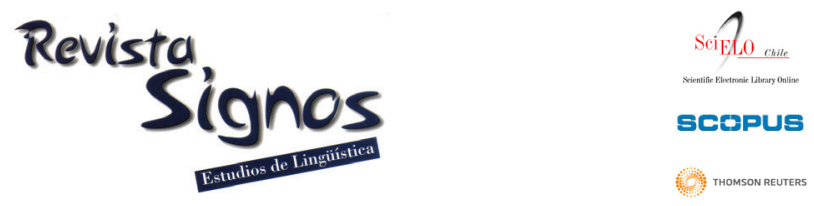

\title{
La controversia en la televisión catalana: "No diga mentiras, señor González"
}

\section{The controversy in the Catalan TV: "Don't lie, Mr González"}

\author{
Margarida Bassols \\ Universidad Autónoma de Barcelona \\ ESPAÑA \\ Anna Cros \\ margarida.bassols@uab.cat \\ Anna Torrent \\ Universidad Autónoma de Barcelona \\ ESPAÑA \\ anna.cros@uab.cat \\ Universidad Autónoma de Barcelona \\ ESPAÑA \\ anna.torrent@uab.cat
}

Recibido: 16-VI-2012 / Aceptado: 5-IV-2013

\section{Resumen}

El objetivo de este trabajo es analizar cómo se exterioriza el desacuerdo en un contexto de escena plural y, para ello, se centra en el estudio de la microcontroversia sobre el coste de la energía nuclear, que se da en el debate televisivo titulado ¿La energía nuclear es un peligro?, del programa Els matins de Televisió de Catalunya. Se parte de la propuesta teórica de Dascal (1995a, 1995b), que sugiere la observación de cuatro componentes: dinámico (fases y deslizamiento temático), morfológico (encadenamiento sintáctico y semántico-lógico), pragmático (posicionamiento del hablante respecto a sus enunciados) y retórico (aspectos persuasivos e ideológicos). En la microcontroversia analizada, la propuesta de Dascal (1995a, 1995b) se configura con estos rasgos: pese a su brevedad, se dan tres fases de intensidad agónica distinta; se debate sobre el tema principal, pero también sobre otros temas más o menos relacionados, a conveniencia de los debatientes; el encadenamiento del discurso de las intervenciones está pautado principalmente por los marcadores iniciales, casi siempre modalizadores; los enunciados -asertivos, directivos o expresivos- presentan distintos grados de solidez, como reflejo de la seguridad o inseguridad de los debatientes respecto a sus propias palabras; y los argumentos esgrimidos se despliegan con una habilidad diversa. Todo ello provoca que haya un debatiente ganador, frente a los perdedores. En conclusión, la controversia televisiva favorece la espectacularización de la palabra, ayudada por la imagen; su formato se desarrolla en pocos minutos, como si el medio no soportara una larga confrontación; y los debatientes, a menudo dominados por el pathos, solo intentan defender su punto de vista -no les importa llegar a la verdad-y quedar bien ante la audiencia.

Palabras Clave: Controversia, televisión, divulgación, argumentación, retórica. 


\begin{abstract}
This paper seeks to analyze how disagreement is displayed in a context of a plural scene focusing on the analysis of the microcontroversy on the cost of the nuclear energy. Our data comes from the TV debate "Is nuclear power a danger?" aired in the Els matins of Televisió de Catalunya. The study is informed by the four-component framework proposed by Dascal's (1995a, 1995b): dynamic component (phases and thematic slide) morphological component (syntactic, semantic and logical chains), pragmatic component (debaters' positioning regarding their statements) and rhetorical component (persuasive and ideological aspects). In the microcontroversy studied, Dascal's (1995a, 1995b) work isconfigured with these features: despite its brevity, there are three distinct phases of agonizing intensity; the main topic is debated, together with other more or less related issues, according to the debaters' needs; the flow of the speech is mainly connected by initial markers, usually modals; the utterances assertive, directive or expressive- present varying degrees of strength, as a reflection of the debaters' self-assertion in relation with their own words; and the arguments are deployed with different skills. In consequence, there is a winning debater and the rest are portrayed as losers. In conclusion, controversy fosters television show of the word, aided by images and by the fact that it takes place in a few minutes, as if the media was not able to support a long confrontation, and the debaters, often dominated by the pathos, only try to defend their point of view to get the best impression from the audience -without necessarily getting to the truth.
\end{abstract}

Key Words: Controversy, television, popularization, argumentation, emotionalization, rhetoric.

\title{
INTRODUCCIÓN
}

Los debates televisivos pueden llegar a un grado de viveza y de confrontación extraordinario, y este es el caso que se analiza en este trabajo. A partir de la pregunta "¿La energía nuclear es un peligro?” (Els matins de TV3), los seis participantes invitados procedentes de los ámbitos académico, asociativo y empresarial, moderados por un conductor experto, desarrollan un diálogo donde cada uno intenta que su punto de vista prevalezca. En este marco, el objetivo del artículo es analizar cómo se exterioriza el desacuerdo en un contexto de escena plural y, para ello, se centra en el estudio de las características de una de las microcontroversias que se dan en este debate, concretamente la que trata sobre el precio de la energía.

La lingüística se ha acercado desde distintas perspectivas (la pragmática, la pragmadialéctica, el análisis conversacional, el análisis del discurso, la gramática textual, la teoría de los géneros...) al estudio del funcionamiento de las discusiones de la vida cotidiana y de los debates del mundo mediático y político, en definitiva, de la confrontación más o menos apasionada de opiniones; pero se ha centrado sobre todo en la materialización de los argumentos, los actos de habla y los recursos retóricos. 
Las aportaciones de Perelman y Olbrechts-Tyteca y de Van Eemeren, Weston, Roulet, Walton y Charaudeau, por ejemplo, han supuesto un avance importantísimo en este sentido.

Pero desde nuestro punto de vista, el análisis de un dispositivo locutivo plural como es la controversia, donde se tratan distintos temas y en el que se defienden las opiniones con mucha vehemencia, además de atender a la estructuración de la opinión de cada uno de los participantes, debe tener en cuenta 'la construcción plural del sentido'. Por esta razón, hemos querido detectar la relación entre las opiniones, la estructuración de los temas y el sentido general a lo largo del debate y dentro de cada una de las microcontroversias que lo configuran.

Para ello nos ha sido de gran utilidad el marco teórico que construye Dascal (1995a, 1995b), ya que ofrece la posibilidad de analizar de un modo más completo el funcionamiento de estas microcontroversias, a partir de la observación de cuatro componentes: morfológico, pragmático, retórico y dinámico.

Entre los aportes novedosos de nuestro estudio, cabe destacar el análisis del deslizamiento temático y la localización de la génesis de los subtemas, la constatación de la estructura de poder desequilibrada entre los debatientes y de las estrategias que favorecen el papel dominante de uno de ellos por encima de los demás; el funcionamiento de los distintos tipos de marcadores de lucha por el turno de habla, la determinación clara de las fases de las microcontroversias y de los actos que las materializan, la detección de las falacias ad hominem, non-sequitur y 'de división' como las más usadas y el papel central de las ejemplificaciones, las preguntas retóricas y las repeticiones en el componente retórico. Y, por otra parte, los movimientos de la cámara para captar la idiosincracia, la emocionalización y el saber estar de los debatientes.

\section{Marco teórico}

\subsection{Características de la controversia}

La definición de controversia que ofrece Dascal (1995a, 1995b), en el marco de análisis de la pragmática y de sus reflexiones sobre la historia de las ideas y la epistemología, es la de una actividad discursiva que pertenece a la categoría del diálogo; se manifiesta en los intercambios lingüísticos, escritos u orales (debates públicos, coloquios, etc.), que denomina genéricamente 'polémica'; ocupa una posición intermedia entre la discusión y la disputa, y se caracteriza lingüísticamente por los 'marcadores de oposición' (ej. "no estoy de acuerdo", "usted no puede decir que...", "lo que usted dice contradice...") que resaltan su carácter agónico. La controversia se caracteriza esencialmente por:

a) El carácter dinámico de la problemática. Las controversias no quedan confinadas a los problemas iniciales que las motivan, sino que se amplían, tanto en extensión como en profundidad, de manera que los temas evolucionan y cambian. 
b) El carácter generalizador de la discusión, que provoca que los interlocutores no solo cuestionen las tesis de los adversarios sino también los principios, los métodos y los valores.

c) El carácter hermenéutico de la interacción. No se trata de poner en juego únicamente la verdad o los hechos, sino también las interpretaciones de las ideas, de los datos y del lenguaje:

"En cada paso los contendientes se acusan mutuamente de presentar incorrectamente las tesis del Otro, de emplear un lenguaje ambiguo, de no contestar a las objeciones, y de no centrarse en el 'verdadero problema' que hay que resolver, ya sea en una fase determinada de la controversia, ya sea en general"' (Dascal, 1995a: 19).

d) El carácter abierto y flexible (pero no anárquico) de la estructura de la interacción, que provoca la imposibilidad de anticipar la deriva de la discusión, los argumentos y las objeciones aportados por los interlocutores.

e) El carácter no conclusivo, por el que las controversias no son resolubles, como la discusión, ni irresolubles (racionalmente), como la disputa. Tienden a ser largas, inconclusas y reciclables. Las controversias no nos permiten vencer, ni convencer ni resolver el problema pero, indirectamente, nos permiten comprender mejor este problema, las posiciones de los demás y las dificultades que surgen para enfrentarse a ellas:

"La resolución puede consistir en el reconocimiento (por parte de los contendientes o de su comunidad de referencia) de que se ha acumulado suficiente peso en favor de una de las posiciones, o bien en la aparición de posiciones modificadas (gracias a la controversia) aceptables para los contendientes, o simplemente en la aclaración recíproca de la naturaleza de las divergencias en juego" (Dascal, 1995b: 17).

Dascal (1995a, 1995b) considera que una teoría de las controversias interesada también en el papel epistemológico debe comprender cuatro componentes:

- Un componente morfológico, que analice el encadenamiento sintáctico y semántico-lógico de las intervenciones.

- Un componente pragmático, que incluya las cuestiones de interpretación y de constitución dialógica del sentido. Debería resolver el problema que presenta un tipo de conversación a la vez cooperativo y conflictivo como la controversia.

- Un componente retórico, que estudie las estrategias de persuasión y los aspectos ideológicos.

- Un componente dinámico, que aclare cuáles son las fases de la controversia, cómo evolucionan y cómo acaban. El deslizamiento temático (tema-rema) tiene un 
papel especial, porque obedece a una regularidad que corresponde a una fase de 'divergencia' (exploración de temas en relación horizontal), seguida de una fase 'de profundización y convergencia' (búsqueda de las fuentes profundas de divergencia) $y$, finalmente, de una fase de aplicación (descubrimiento de temas o de ejemplos adicionales derivados de esta diferencia profunda).

Aunque como dice Shiffrin (1994), el análisis conversacional no se centra en las estructuras lingüísticas sino en las estructuras secuenciales (pares adyacentes, turnos de palabra, solapamientos...), desde este ámbito de estudio se han dado aportaciones interesantes referidas a las partículas. En este aspecto, para analizar la organización de los intercambios lingüísticos de la controversia, nos resultará útil centrarnos en aquellas partículas que orientan y desvían el hilo argumentativo de los hablantes: los marcadores de inicio de turno que, según Cuenca y Marín (2006), adoptan funciones estructurales, modalizadoras y proposicionales.

\subsection{La controversia en la televisión}

El medio televisivo convierte la controversia en una forma de habla institucional, que tiende a fijar el rol de los participantes y que potencia el efecto las emociones. En esta línea, Hutchby (2006), en su análisis sobre el habla de los medios de comunicación en el marco del Análisis de la Conversación, considera que el contexto en que se produce este tipo de interacción (Media Talk) lo convierte en una forma de habla institucional o no conversacional. La televisión es un lugar institucional ideal para el opinionated talk. De entre los formatos de habla diferentes que aparecen en la televisión, la controversia suele surgir en contextos formales, donde la gestión de los turnos de palabra se diferencia sustancialmente de la conversación y donde, a menudo, los turnos asignados a los participantes están muy marcados, especialmente en las entrevistas:

"Formal systems are those in cabestrante 'the institutional' character of the interaction is embodied first and foremost in its form -most notably in turn-taking systems which depart substantially from the way in which turn-taking is managed in conversation" (Hutchby, 2006: 26).

En estos contextos, según este autor, los invitados interpretan el papel de 'desafiante' y 'oponente', y justifican sus opiniones mediante argumentos, mientras que el conductor hace de mediador y licita, con preguntas, la posición o las versiones de los acontecimientos de los antagonistas. Esto implica, por un lado, que los turnos opuestos no suelen ser adyacentes, porque es necesaria una pregunta del conductor. Por otro lado, que el desacuerdo no se suele manifestar directamente al oponente, sino al entrevistador, disminuyendo, así, el grado de confrontación (los participantes se dirigen a los antagonistas en tercera persona, no en primera). De todos modos, según Hutchby (2006), la espectacularización de los programas provoca que, en algunos momentos, el conductor permita el enfrentamiento directo entre los participantes, 
asegurándose de volver a mantener el control del intercambio cuando le parece conveniente.

Las consideraciones de este autor son coincidentes con los estudios sobre la argumentación realizados en el marco de la pragmadialéctica, que destacan el carácter agónico de la lucha de opiniones en esta etapa de confrontación (van Eemeren, Grootendorst, Jackson \& Jacobs, 1993), aquella en la que lo más importante es defender la exclusividad de las propias razones y la irracionalidad del oponente, y en la que las emociones, que suelen exteriorizarse en un contexto de lucha donde el pathos aflora, son potenciadas por el medio televisivo, principalmente a través de las imágenes.

En nuestro análisis, por lo que respecta a la imagen televisiva, es decir a los distintos planos de los debatientes y el moderador, adoptaremos la lectura que hace Compte (2009) de la semiótica multimodal formulada por Kress y Van Leeuwen (2001) y, concretamente, la propuesta que la semiótica vehiculada por el canal vídeo puede 'facultar' o 'complementar' la emitida por el canal audio, o a la inversa. De acuerdo con Compte (2009), consideraremos que, entre la información difundida por los dos canales, se pueden producir tres tipos de relación: 'redundancia', cuando la información transmitida por los canales vídeo y audio coincide; 'complementariedad', cuando la información de un canal complementa la del otro; y 'oposición', cuando la información de un canal discrepa de la del otro.

Finalmente, y aunque sea un tema tangencial en nuestro trabajo, nos referiremos sucintamente a la emocionalización, ya que está presente en toda situación de lucha. Para ello, tendremos en cuenta la propuesta de Bradley y Lang (1994), que sostienen que las tres dimensiones subyacentes a cualquier emoción son la 'valencia' (grado de positividad o negatividad), la 'excitación' (alta, mediana, baja...) y el 'dominio' (percepción del control personal). La manifestación de estas tres dimensiones puede mejorar o empeorar la imagen de los debatientes y su credibilidad, y crear, según el caso, una atmósfera afectiva de amplio espectro, que va de la satisfacción al desasosiego.

Así, en la minicontroversia analizada, las expresiones faciales de sorpresa, desprecio y enojo, aunque en principio, pueden colaborar al descrédito más o menos explícito del contrario, también pueden provocar el efecto opuesto, y desprestigiar a la persona que las produce, ya que exteriorizan sus emociones negativas y un alto grado de excitación y de descontrol, indicio de su falta de dominio en una situación de controversia pública.

\section{Marco metodológico}

Se seleccionó el programa Els matins después de haber estudiado los otros programas emitidos por Televisió de Catalunya que respondían al formato de 'debate'. 
El repaso de sus emisiones nos permitió observar que la mayor parte de ellos no ofrecían verdaderos enfrentamientos dialécticos, sino una exposición sucesiva de puntos de vista, vehiculados a través de monólogos encadenados, que raramente se enfrentaban. En el programa seleccionado, en cambio, se detectaban algunos momentos de confrontación y esto permitía el análisis de la controversia atendiendo a las expresiones verbales, pero también a los movimientos de la cámara.

\subsection{Els matins amb Josep Cuní (2004-2011)}

El programa Els matins es un magazine de información y entretenimiento, ofrecido en directo de lunes a viernes (de $8 \mathrm{~h}$ a $13 \mathrm{~h}$ ), y producido por TVC en colaboración con Broadcaster TRV Producciones. Tiene distintas secciones: un bloque informativo, una entrevista, una tertulia, una serie de microsecciones (bolsa de trabajo, medio ambiente, salud...), espacios dedicados a los sucesos, un análisis de la actualidad, y (en la última franja de $12.15 \mathrm{~h}$ a $13 \mathrm{~h}$ ) debates o coloquios.

\subsubsection{Participantes}

En el debate analizado, de 28 minutos, el conductor plantea la pregunta: ‘'La energía nuclear es un peligro?’ a la audiencia y a los invitados, que son: PEP PUIG (D1), profesor de Energía de la Universidad Autónoma de Barcelona; ANNA ROSA MARTÍNEZ (D2), coordinadora delegada de Greenpeace en Cataluña; MARCEL CODERCH (D3), secretario de la Asociación para el Estudio de Recursos Energéticos; EDUARDO GONZÁLEZ (D4), presidente del Foro de la Industria Nuclear Española; MARIANO MARZO (D5), catedrático de Recursos Energéticos y Geología del petróleo de la Universidad de Barcelona, y XAVIER DÍEZ (D6), catedrático de Ingeniería Nuclear de la Universidad Politécnica de Cataluña. Se invita, pues, a tres representantes del ámbito académico universitario (dos de ellos catedráticos) de las tres grandes universidades catalanas; a dos representantes del ámbito del activismo social y al presidente de un organismo que representa a las empresas nucleares españolas, por parte del mundo empresarial.

\subsubsection{Lugar, disposición y cámara}

Plató de TV3. Los debatientes están sentados en semicírculo. El conductor del programa está sentado en el centro y tiene tres locutores a cada lado: a la derecha, los que se oponen a la energía nuclear (D1, D2, D3), y a la izquierda los que la defienden total o parcialmente (D4, D5, D6).

Abundan los planos medios del participante que tiene la palabra, y, en este caso, la cámara muestra la redundancia entre el mensaje verbal y el icónico (por ejemplo, palabras irritadas con cara y gestos de irritación; palabras calmadas con cara y gestos de tranquilidad). En otras ocasiones, la cámara se desplaza para enfocar a los tres debatientes que defienden el mismo punto de vista: también en este caso observamos 
redundancia en los dos canales, audio y vídeo, ya que el discurso del que tiene la palabra provoca muestras de asentimiento en el rostro de sus adeptos, porque lo comparten. Finalmente, la cámara puede también enfocar a los tres debatientes que disienten de lo que el hablante defiende, y los dos canales no vehiculan un mensaje unitario, ya que las imágenes muestran oposición a las palabras que en aquel momento el debatiente contrario formula. En definitiva, la imagen permite captar la opinión de los debatientes, y también su personalidad, su estado de ánimo y su capacidad para sostener su punto de vista, no solo cuando hablan, sino también cuando escuchan.

\subsubsection{La controversia de Els matins}

El programa de TV analizado en este estudio se encontraría a mitad de camino entre los dos tipos de controversia señalados por Charaudeau (2010): la científica y técnica, y la social. Se acerca a la primera porque se trata un tema especializado y porque todos los participantes quedan legitimados e igualados por el hecho de que representan alguna institución socialmente reconocida. A través del análisis, sin embargo, veremos que se trata de una falsa simetría. Y se acerca a la controversia social porque el discurso se produce en la televisión, porque se problematiza moralmente el tema y porque el objetivo no es llegar a grandes acuerdos. Como es propio de este medio, los participantes hablan entre sí pero también para los telespectadores. A diferencia, sin embargo, del objetivo ideal que, según Charaudeau (2010), llevaría a una negociación con la voluntad de conseguir un bien colectivo, se podría decir que las diferencias entre los invitados son irreductibles. Al final del debate, las posturas de los debatientes no se modifican, pero se encuentran en un campo común cuando hablan de que reducir el consumo energético es la única salida razonable a la situación.

En cuanto al formato, el programa que analizamos se puede relacionar con el tipo de actividad que Hutchby y otros autores denominan panel (panel), en la que un entrevistador-moderador (chair) conduce una interacción entre unos participantes invitados al programa y seleccionados porque provienen de ámbitos diferentes y defienden posiciones encontradas sobre un mismo tema. El desacuerdo, pues, es una característica intrínseca del encuentro y, en este contexto, se permite una interacción combativa entre los participantes.

\subsubsection{La microcontroversia sobre el precio de la energía}

La microcontroversia sobre el precio de la energía se inicia al cabo de ocho minutos de haber empezado el debate y D4 sustenta firmemente su opinión sobre el beneficio de la energía nuclear mientras D1 y D2 se lo discuten. Se puede decir que D4 se constituye como el protagonista de este fragmento y D1 y D2 como sus antagonistas. En muchas ocasiones, se solapan las intervenciones de los locutores porque no respetan el turno de palabra (de 29 intervenciones, 17 pisan el turno de habla del otro). Esto es una muestra del carácter agónico del fragmento analizado. 
Siguiendo la tónica del programa, la cámara enfoca, en un plano medio, la persona que habla; sin embargo, en los momentos de más lucha por el turno de palabra, pasa del plano medio al plan de conjunto para mostrar la reacción de todos los debatientes. Los cambios de plano permiten ver la postura corporal, la expresividad de la cara y la gesticulación de los debatientes, así como captar la calidad de las voces. El cuadro 1, relaciona el discurso oral de los hablantes con su gestualidad y con los elementos paralingüísticos que emplean, y también con los enfoques y movimientos de cámara.

\begin{tabular}{|c|c|c|c|}
\hline & Discurso oral & Géstica y paralenguaje & Cámara \\
\hline 12:10:57 & $\begin{array}{l}\text { D4: La energía nuclear, sobre todo, } \\
\text { nos proporciona una electricidad más } \\
\text { barata que el resto de las energía }\end{array}$ & $\begin{array}{l}\text { Mira hacia el conductor. Hace } \\
\text { un gesto horizontal con una } \\
\text { mano (para acabar el tema) } \\
\text { Cuerpo apoyado en la silla }\end{array}$ & $\begin{array}{l}\text { Pasa de plano de con- } \\
\text { junto a plano medio } \\
\text { (D4) }\end{array}$ \\
\hline \multirow[t]{2}{*}{ 12:11:02 } & $\begin{array}{l}\text { D1: Fent trampa comptablement } \\
\text { 'Haciendo trampa contablemente' }\end{array}$ & $\begin{array}{l}\text { D4 indica que no con la } \\
\text { cabeza } \\
\text { D1 hace cara de escepticismo. } \\
\text { Tono indignado }\end{array}$ & $\begin{array}{l}\text { Pasa de plano medio } \\
\text { de D4 a plano medio } \\
\text { de D1 }\end{array}$ \\
\hline & $\begin{array}{l}\text { D4: No, no, no, que el resto de las } \\
\text { energías }\end{array}$ & & Plano medio de D1 \\
\hline \multirow[t]{2}{*}{ 12:11:05 } & $\begin{array}{l}\text { D2: }[(\text { Perquè nosaltres estem subvencio- } \\
\text { nant...) }] \text { 'Porque nosotros la estamos } \\
\text { subvencionando' }\end{array}$ & & Plano medio de D4 \\
\hline & $\begin{array}{l}\text { D4: [(Y forma parte, y forma parte de } \\
\text { la solución. })]\end{array}$ & & Plano medio de D4 \\
\hline 12:11:09 & $\begin{array}{l}\text { D2:...les despeses dels residus, per exemple, } \\
{[(\text { en gran part. Hombre! })] \text { 'los gastos de }} \\
\text { los residuos, por ejemplo, en gran } \\
\text { parte' }\end{array}$ & $\begin{array}{l}\text { Mira a D4. Cuerpo hacia } \\
\text { delante. Gesticula y cruza los } \\
\text { brazos cuando dice 'Hombre' }\end{array}$ & Plano medio de D2 \\
\hline 12:11:11 & $\begin{array}{l}\text { D4: }[\text { No. })] \text { Los residuos están finan- } \\
\text { ciados en la tarifa. O sea, lo que paga- } \\
\text { mos todos los días por la electricidad } \\
\text { paga los residuos.)] }\end{array}$ & $\begin{array}{l}\text { D4: mira a D2 } \\
\text { Cuerpo apoyado en la silla. } \\
\text { Poca gesticulación } \\
\text { D2: brazos cruzados } \\
\text { Cara de indignación } \\
\text { Intenta interrumpir } \\
\text { D4: cara de condescendencia, } \\
\text { mientras mira a D2 }\end{array}$ & $\begin{array}{l}\text { Plano medio de D4 } \\
\text { Plano medio de D2 } \\
\text { Plano medio de D4 }\end{array}$ \\
\hline 12:11:16 & $\begin{array}{l}\text { D2: [(Exacte, el que paguem cada dia } \\
\text { nosaltres.)] 'Exacto, lo que pagamos } \\
\text { cada día nosotros' }\end{array}$ & Cara de indignación & $\begin{array}{l}\text { Pasa de plano medio } \\
\text { de D4 a medio de D2 }\end{array}$ \\
\hline 12:11:17 & $\begin{array}{l}\text { D4: Hombre... Pagamos e: } 2 \text { cénti- } \\
\text { mos de euro por kw/h. O sea que... }\end{array}$ & $\begin{array}{l}\text { Mira a D2. Cuerpo apoyado } \\
\text { en la silla } \\
\text { Poca gesticulación. } \\
\text { Cara de obviedad }\end{array}$ & Plano medio de D4 \\
\hline 12:11:22 & $\begin{array}{l}\text { D1: Escolti, [(expliqui tota la bistòria, } \\
\text { expliqui tota la història...)] 'Escuche, } \\
\text { explique toda la historia, explique toda } \\
\text { la historia' }\end{array}$ & $\begin{array}{l}\text { D1 mira a D4 } \\
\text { Gesticula con los dos brazos }\end{array}$ & $\begin{array}{l}\text { Plano de conjunto de } \\
\text { los tres debatientes } \\
\text { anti: D1, D2 y D3 }\end{array}$ \\
\hline
\end{tabular}




\begin{tabular}{|c|c|c|c|}
\hline & D4: [(Vamos a ver, vamos a ver.)] & $\begin{array}{l}\text { Cuerpo apoyado en la silla } \\
\text { Poca gesticulación: gesto } \\
\text { como si quisiera parar el } \\
\text { discurso de D1 }\end{array}$ & Plano medio de D4 \\
\hline \multirow[t]{2}{*}{ 12:11:23 } & $\begin{array}{l}\text { D1: }[(\ldots \text { des del començament... })] \text { 'desde el } \\
\text { comienzo' }\end{array}$ & $\begin{array}{l}\text { Mira a D4. Gesticula con las } \\
\text { dos manos }\end{array}$ & Plano medio de D1 \\
\hline & D4: [(Entonces: $]]$ & & Plano medio de D1 \\
\hline \multirow[t]{2}{*}{ 12:11:24 } & $\begin{array}{l}\text { D1: [(... com es va fer la nuclear en aquest } \\
\text { pais...)] 'cómo se hizó la nuclear en } \\
\text { este país...' }\end{array}$ & & Plano medio de D1 \\
\hline & D4: Vamos a ver.[Las...] & $\begin{array}{l}\text { Mira a D1 con cara de } \\
\text { cansado }\end{array}$ & Plano medio de D4 \\
\hline 12:11:26 & $\begin{array}{l}\text { D1: [(...en règim)] de dictadura, tots els } \\
\text { privilegis que es van donar a les empreses } \\
\text { elèctriques; que les empreses elèctriques es van } \\
\text { donar, van arribar a una situació financera } \\
\text { de pràcticament fallida...] '...en régimen } \\
\text { de dictadura, todos los privilegios que } \\
\text { se dieron a las empresas eléctricas; que } \\
\text { las empresas eléctricas se dieron, llega- } \\
\text { ron a una situación de prácticamente } \\
\text { quiebra...' }\end{array}$ & & Plano medio de D1 \\
\hline 12:11:34 & D4: $[($ Hombre, no es eso....)] & $\begin{array}{l}\text { Ríe y hace un gesto de can- } \\
\text { sancio con la mano derecha. } \\
\text { Niega con la cabeza }\end{array}$ & Plano medio de D4 \\
\hline 12:11:36 & $\begin{array}{l}\text { D1:...com se'ls va treure de la fallida. Clar. } \\
\text { Vull dir no expliqui l'última part de la } \\
\text { història [(dient que és barata perquè no és } \\
\text { veritat)] '... cómo se las sacó de la quie- } \\
\text { bra. Claro. Quiero decir no explique } \\
\text { la última parte de la historia diciendo } \\
\text { que es barata porque no es verdad' }\end{array}$ & $\begin{array}{l}\text { Mira a D4 } \\
\text { Gesticula con las dos manos } \\
\text { Hace un gesto de obviedad } \\
\text { cuando dice "claro" }\end{array}$ & Plano medio de D1 \\
\hline 12:11:38 & D4: [Pero vamos...] & Sonríe con condescendencia & Plano medio de D4 \\
\hline 12:11:41 & $\begin{array}{l}\text { C: Senyor González. 'Señor Gon- } \\
\text { zález' }\end{array}$ & & \\
\hline 12:11:43 & $\begin{array}{l}\text { D4: Yo creo que podemos analizar la } \\
\text { historia pero estamos en la situación } \\
\text { que estamos y tenemos lo que tene- } \\
\text { mos. Entonces, las centrales nucleares } \\
\text { hoy en España suministran, más o } \\
\text { menos, la quinta parte de la energía } \\
\text { eléctrica y son, de las que funcionan } \\
\text { suministrando a las eléctricas, las más } \\
\text { baratas. En parte, su coste es el que } \\
\text { permite financiar, por ejemplo, eee las } \\
\text { las eólicas que están en operación. }\end{array}$ & $\begin{array}{l}\text { Habla con una media sonrisa } \\
\text { todo el rato. Gesticula con } \\
\text { las dos manos, sin cambiar } \\
\text { la postura del cuerpo. Marca } \\
\text { algunos énfasis en el discurso }\end{array}$ & Plano medio de D4 \\
\hline 12:12:06 & $\begin{array}{l}\text { D1: [(No és veritat. Això no és veritat.)] } \\
\text { 'No es verdad. Esto no es verdad.' }\end{array}$ & & Plano medio de D4 \\
\hline 12:12:08 & $\begin{array}{l}\text { D2: [( Això: té documentació per comprovar- } \\
\text { ho?)] '¿Esto tiene documentación para } \\
\text { comprobarlo?' }\end{array}$ & $\begin{array}{l}\text { Mano izquierda y cara acen- } \\
\text { túan la indignación hacia D4 }\end{array}$ & $\begin{array}{l}\text { Plano medio lateral } \\
\text { de D1 }\end{array}$ \\
\hline
\end{tabular}




\begin{tabular}{|c|c|c|c|}
\hline & D4: [(Perdón perdón perdón.)] & $\begin{array}{l}\text { Hace un gesto con la mano } \\
\text { para parar la interrupción y } \\
\text { cierra los ojos. }\end{array}$ & Plano medio de D4 \\
\hline & $\begin{array}{l}\text { D1: [Això no és veritat, senyor.)] 'Esto } \\
\text { no es verdad, señor.' }\end{array}$ & Mano levantada hacia D4 & Plano de conjunto \\
\hline & $\begin{array}{l}\text { D2: }[(\text { Com pot dir això? })] \text { '¿Cómo pue- } \\
\text { de decir esto?' }\end{array}$ & $\begin{array}{l}\text { Cuerpo hacia delante y gesti- } \\
\text { culación }\end{array}$ & Plano de conjunto \\
\hline & D4: [(Sí, sí, sí.)] & & Plano de conjunto \\
\hline & $\begin{array}{l}\text { D1: [No digui mentides!] ‘'No diga } \\
\text { mentiras!' }\end{array}$ & & Plano de conjunto \\
\hline 12:12:11 & $\begin{array}{l}\text { D4: Pero, hombre, haga usted los } \\
\text { números, haga usted los números en } \\
\text { su totalidad. }\end{array}$ & $\begin{array}{l}\text { D4 (a D1): Apoyado en la } \\
\text { silla. Gesticula con la mano } \\
\text { derecha y habla en un tono } \\
\text { condescendiente }\end{array}$ & Plano de conjunto \\
\hline
\end{tabular}

Cuadro 1. Transcripción de la microcontroversia, la géstica y los movimientos de cámara.

\section{Análisis de la microcontroversia sobre el precio de la energía}

Siguiendo las propuestas de Dascal (1995a, 1995b), nos centraremos en cuatro niveles de análisis: el dinámico, el morfológico, el pragmático y el retórico. Dado el carácter mediático de la microcontroversia, analizaremos también el comportamiento de la cámara como vehículo para la potenciación de las emociones.

\subsection{Dinámica de la controversia}

En este apartado observaremos cómo se configura el sentido de la discusión y cómo se interrelacionan las intervenciones.

La progresión temática del debate en general es de tipo amplificador. Tal como dice Dascal (1995a, 1995b), los temas evolucionan a lo largo de la polémica, de manera que se produce un 'deslizamiento temático' respecto del término base, la energía nuclear. Así, se dan tres grandes etapas en el desarrollo del debate. Un primer momento, expositivo, cargado de actos de habla asertivos, que marcan las posiciones de manera objetiva. Un segundo momento, de manifestación del desacuerdo a partir de adverbios y expresiones irónicas que llegan a ser, en algunos casos, un poco descorteses. Y un tercer momento de ataque frontal. Podemos decir, pues, que el clímax del debate aumenta pasando de una perspectiva 'objetiva' a un nivel de subjetividad muy notable.

Pero, si esquematizamos las ideas que surgen durante la microcontroversia analizada (separando los momentos en los que cambia el proponente y, por tanto, también el oponente), el resultado es el siguiente: 


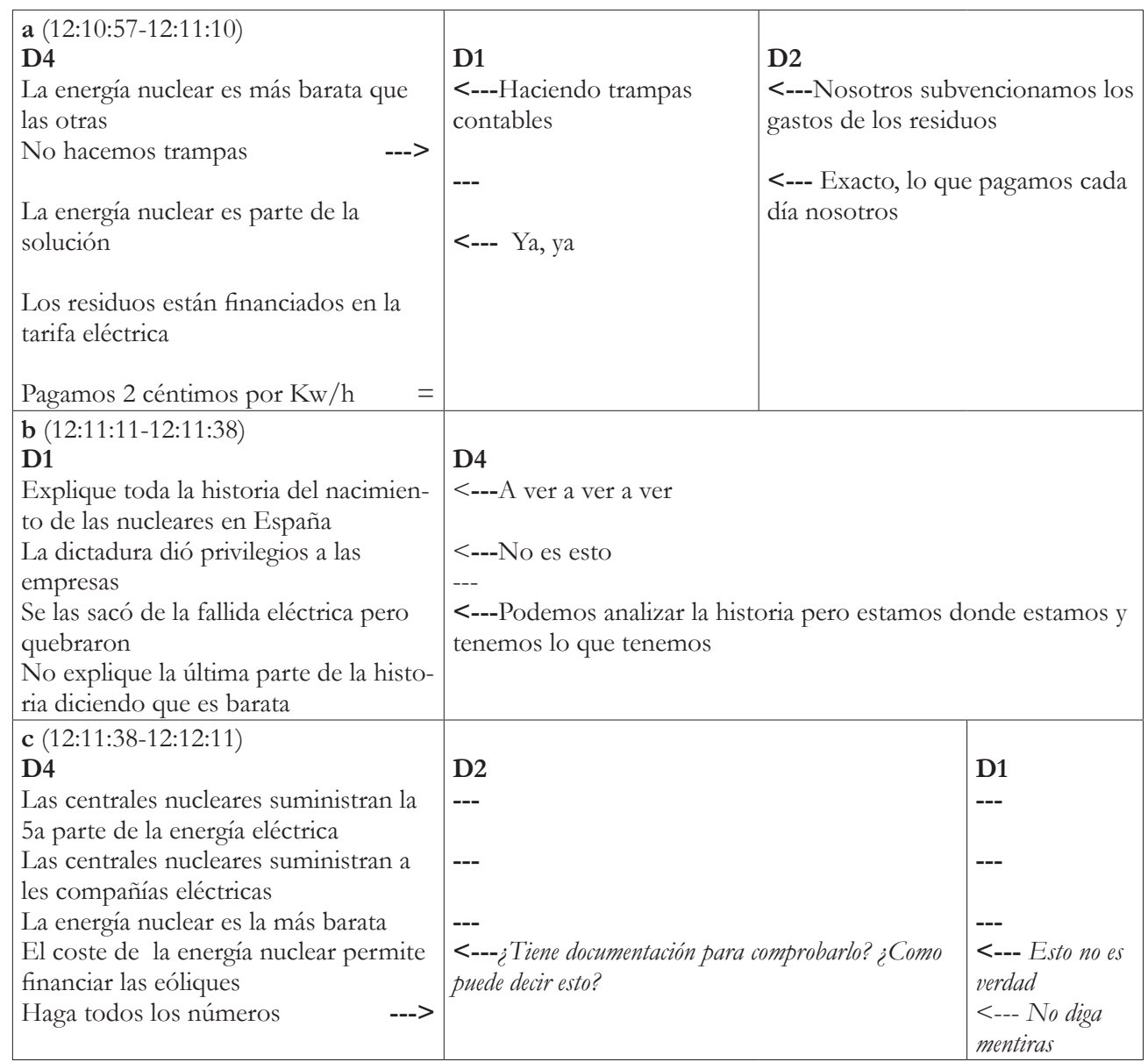

Cuadro 2. Esquematización de las ideas sobre el precio de la energía.

En cuanto al nivel enunciativo de las confrontaciones, se observa que algunas contraargumentaciones se basan en el contenido proposicional de lo dicho por el oponente, en lo que ha dicho ("La energía nuclear es más barata que las otras" dice D4, "haciendo trampas contables", rebate D1). Y que otras lo hacen en el acto comunicativo, en la enunciación ("el coste de la energía nuclear permite financiar las eólicas” afirma D4; “¿cómo puede decir eso?”, rebate D1). Además, pragmáticamente hablando, algunas contraargumentaciones trabajan sobre lo dicho explícitamente por el locutor contrario, como las anteriores, pero otras lo hacen sobre lo implicado ("Exacto, lo que pagamos cada día nosotros", dice D2, refiriéndose a lo implícito que D4 esconde intencionadamente: que los usuarios pagan en parte la energía nuclear en la tarifa eléctrica). 


\subsection{Morfología de la controversia}

La morfología de la controversia se refiere al encadenamiento sintáctico y semanticológico de las intervenciones (Dascal, 1995a, 1995b), y, por lo tanto, en ella tienen un papel determinante los marcadores discursivos de inicio de turno, que pueden ser de categorías diversas: conjunciones, interjecciones, adverbios, verbos de percepción gramaticalizados, vocativos y otros elementos sintagmáticos, a menudo dichos más de una vez. Los marcadores iniciales son elementos fundamentales en el establecimiento de la dinámica de la microcontroversia, porque nos indican con bastante claridad cómo se estructura, cómo evoluciona y como termina, qué fases son más relajadas y cuáles más agónicas; e incluso qué debatientes se erigen en ganadores y cuáles en perdedores. Como observan Cuenca y Marín (2006), las funciones que realizan estos marcadores son estructurales (delimitación de secuencias, distribución de turno, aceptación de turno, lucha por el turno), modalizadoras (acuerdo, desacuerdo, contraposición), y proposicionales (de adición, de disyunción, de contraste y de consecuencia), aunque a menudo un marcador ejerce mas de una función. En esta microcontroversia, todos los marcadores iniciales, sea cual sea la función principal que realicen, se vinculan a la lucha por el turno, lo cual hay que relacionarlo con la escasa ritualización que se percibe y con las intervenciones libres y precipitadas de los debatientes.

Precisamente por esta escasa ritualización, los marcadores estructurales propiamente dichos tienen muy poca presencia: el moderador no suele delimitar las secuencias, ni distribuir los turnos ni quitar la palabra a nadie; y los debatientes no explicitan nunca la aceptación de turno, sino que intervienen directamente, aunque sea solapando su discurso al de otros. De hecho, solo aparece un marcador estructural: el vocativo que utiliza el conductor, asumiendo su autoridad discursiva, para dar el turno de palabra a uno de los debatientes (D4), en un momento de lucha con D1, es decir, C los interrumpe y elige quien debe hablar con "senyor Gonzálę" 'señor González'.

En cambio, los modalizadores son muy abundantes, sobre todolos de contraposición, seguidos a distancia por los que expresan acuerdo y desacuerdo. Tienen que ver con el modum, es decir, con la enunciación, que refleja la actitud del hablante en el debate. Así encontramos los de contraposición: "No, no, no", "Hombre". "Escuche". "No es verdad", "Esto no es verdad", "No diga mentiras". Y los de acuerdo: "Exacto", "Sí, sí, sî"; y desacuerdo: "Vamos a ver, vamos a ver" y "Perdón, perdón, perdón".

En cuanto a los marcadores proposicionales, se refieren al dictum, es decir, al contenido proposicional del enunciado de cada debatiente. Algunos, como 'pero', tienen también una función modalizadora, subrayada por el marcador siguiente: "pero vamos...", "pero hombre..." y indican contraste y desacuerdo a la vez; como 'entonces'. Mientras que 'perquè' 'porque' es de consecuencia. 


\subsection{Pragmática de la controversia}

Siguiendo a Dascal (1995a, 1995b), en la controversia, la pragmática tiene que ver con cuestiones que tocan a la interpretación y la constitución dialógica del sentido en una situación comunicativa a la vez cooperativa y conflictiva. En la controversia televisiva analizada, las formas y estrategias discursivas que hemos tenido en cuenta, porque propician la interpretación y la construcción de sentido, son el uso de determinados enunciados, los intensificadores, las voces discursivas y la axiología, que utilizan los debatientes y que nos dicen como se posicionan en el discurso polémico, qué voces evocan y qué valores priorizan en los mecanismos expresivos seleccionados para vencer a los contrincantes y convencer a la audiencia.

\subsubsection{Enunciados}

Los debatientes se sirven de tres tipos de enunciados -asertivos, directivos y expresivos-, que aparecen distribuidos desigualmente en las distintas fases de la controversia. En efecto, si observamos la fase inicial, veremos que predominan los asertivos; mientras que en la segunda y la tercera fase, abundan los directivos y expresivos, exponentes de que la confrontación va in crescendo. Por otra parte, también se observa desigualdad en el uso particular de cada locutor, en función de sus intenciones. Veámoslo.

En la primera fase [12:10:57-12:11:21], los locutores D1, D2 y D4 utilizan mayoritariamente enunciados asertivos para sustentar su opinión o rebatir la opinión de los adversarios (nueve primeras intervenciones sobre si la energía nuclear es barata o no, y sobre quién la paga).

En la segunda fase [12:11:22-12:11:40] aparecen los enunciados directivos, cuando D1 interpela D4 sobre el coste histórico de las centrales nucleares en España: lo hace con Imperativos en $3^{a}$ persona (cortesía que marca distancia), positivos ('explique') y negativos ('no explique'), que son respondidos, primero, con fórmulas retardatarias y un poco condescendientes por D4 ("vamos a ver, vamos a ver..."), y expresivas de oposición creciente ("hombre, no es eso..."), acompañadas de sonrisas displicentes. En realidad, D1 utiliza la interpelación como estrategia retórica, ya que sabe la respuesta, como queda claro en los enunciados asertivos ("explique... todos los privilegios que se dieron a las empresas eléctricas..., cómo se les sacó de la quiebra...”). En definitiva, lo que D1 pretende es desenmascarar a su contrincante, ya que considera que miente y oculta información fundamental; en este punto queda como virtual ganador.

En la tercera fase [12:11:41-12:12:11], y propiciado por el hecho de que el conductor le da la palabra, D4 retoma el discurso con enunciados asertivos, esquivando el tema histórico por poco útil, e insistiendo en las ventajas económicas de las nucleares, que incluso posibilitan financiar energía renovable. Esta intervención provoca enunciados de contraposición: el asertivo de D1 ("Esto no es verdad"), los directivos de D2 
(“Esto ¿tiene documentación para comprobarlo?”), y de D1 (“No diga mentiras"), y los expresivos de D2 con pregunta retórica incluida ("¿Cómo puede decir eso?" [ "me sorprende que usted diga algo que yo creo que es falso del todo"]), que a menudo se solapan con las réplicas de D4; los directivos de requerimiento (“...Haga usted los números en su totalidad") y los asertivos (mediante el elemento de polaridad "sí, sí, sí”) de contraposición a lo que niegan D1 y D2 y de reafirmación del propio discurso sobre la financiación de energía renovable con la energía nuclear. Es un final con desacuerdo y crispado, del que sale ganador $\mathrm{D} 4$, porque es el único debatiente que ha mantenido un discurso con un alto grado de asertividad, mientras que el de D1 y D2 son réplicas sin argumentos que les confieran credibilidad.

\subsubsection{Intensificadores}

Los intensificadores son expresiones que permiten dar más fuerza locutiva al discurso. Como señalan Cros, Brunat y González (2012), estas expresiones ponen de manifiesto la postura subjetiva del locutor ante unos hechos, sea porque los magnifican o atenúan (subrayan o limitan su importancia, por ejemplo con cuantificadores), sea porque les añaden una visión emocional (como un diminutivo afectivo o un adjetivo calificativo). En la microcontroversia, los locutores utilizan intensificadores de tipo cuantificador, incluidos los atenuadores y los totalizadores; en cambio, evitan los que tienen un carácter más emocional.

Así, en la primera [12:10:57-12:11:21] y la segunda fase [12:11:22-12:11:40], D4 utiliza intensificadores positivos ('sobre todo', 'más barata') y los antagonistas, atenuadores: D1 ('prácticamente') y D2 ('en gran parte'), con lo cual D4 aparece más seguro y optimista, mientras que D1 y D2 parecen más dubitativos con sus matices. En la tercera fase [12:11:41-12:12:11], D4 matiza más, con atenuadores ('más o menos', 'en parte'), quizás para mostrarse más ecuánime y respetuoso con la realidad, aunque continúa utilizando un intensificador positivo referido a la energía nuclear, ya presente en la primera parte (¡más barata!), que permite mantener la coherencia discursiva. En cuanto a los totalizadores, tanto D4 ('todos') como D1 ('toda la historia', 'todos los privilegios', 'toda la verdad') los utilizan; el primero por su interés en resaltar que todo el mundo (y, por lo tanto, la audiencia del programa) son 'receptores de energía nuclear', el segundo, en cambio, para marcar enfáticamente un implícito: D4 calla información. Al final de la controversia, sin embargo, D4 recrimina a D1 lo mismo, mediante otro totalizador ("Haga usted los números en su totalidad").

\subsubsection{Voces}

De acuerdo con la propuesta de Ducrot (1984) en relación a la polifonía discursiva, consideraremos que en el discurso de los locutores se detectan las voces suscitadas de los enunciadores o la del propio locutor. El grado de implicación con estas voces varía en función de la actitud respecto de lo enunciado. La incorporación de voces permite construir la identidad discursiva de los locutores y legitimar su discurso. 
En la microcontroversia analizada, D4 es el enunciador más presente, tanto cuando él habla como cuando hablan los demás debatientes. Esto hace que tenga un papel primordial. D4 utiliza casi siempre un plural inclusivo ("nosotros"), explícito o no ("pagamos"), cuando formula enunciados asertivos; sin embargo, hacia el final, cuando C le da la palabra, comienza con un "yo creo" contundente, seguido otra vez del plural inclusivo habitual ("podemos analizar", "estamos", "tenemos"); por otra parte, también es el receptor más transparente cuando hablan los demás locutores, D1 y D2, siempre a la defensiva y en papeles francamente secundarios. En cuanto a D2, también utiliza, en general, la primera persona del plural para referirse a todo el colectivo de usuarios de la energía, en el que se incluyen él y la audiencia, pero que parece excluir a D4. Por lo que respecta a D1, aparece como receptor transparente al final de la microcontroversia, cuando D4 le sugiere que "haga bien los números" y, en una ocasión anterior, hace de enunciador hipotético de D4. Por lo tanto, la voz más presente y transparente, como locutor y como receptor, es la de D4, lo que subraya el papel principal que juega en el debate y constituye una prueba mas de la autoridad que cree que tiene, de la seguridad desde la que argumenta y de la disimetría que percibe en el intercambio. Veámoslo sintetizado en el cuadro siguiente:

\begin{tabular}{|c|c|c|c|c|}
\hline Debatientes & $\begin{array}{l}\text { Locutor } \\
\text { transparente }\end{array}$ & $\begin{array}{l}\text { Locutor y receptor di- } \\
\text { luidos en un colectivo }\end{array}$ & $\begin{array}{l}\text { Receptor transpa- } \\
\text { rente }\end{array}$ & $\begin{array}{l}\text { Enunciador de dis- } \\
\text { curso reportado }\end{array}$ \\
\hline D4 & Yo creo & $\begin{array}{l}\text { Nos proporciona } \\
\text { Lo que pagamos todos } \\
\text { Pagamos } \\
\text { Vamos a ver } \\
\text { Podemos } \\
\text { Estamos en la situación } \\
\text { que estamos } \\
\text { Tenemos lo que tene- } \\
\text { mos }\end{array}$ & $\begin{array}{l}\text { Haga usted los } \\
\text { números }\end{array}$ & \\
\hline D2 & & $\begin{array}{l}\text { Nosaltres estem subvencio- } \\
\text { nant 'nosotros estamos } \\
\text { subvencionando' } \\
\text { El que paguem cada dia } \\
\text { nosaltres 'lo que paga- } \\
\text { mos cada día nosotros' }\end{array}$ & & \\
\hline D1 & & & $\begin{array}{l}\text { Sr. Gonzáler, té } \\
\text { documentació? '¿tiene } \\
\text { documentación?' } \\
\text { Com pot dir aixó?? } \\
\text { '¿cómo puede decir } \\
\text { esto?' } \\
\text { Escolti, } \\
\text { expliqui'escuche, } \\
\text { explique' } \\
\text { No expliqui 'no } \\
\text { explique' } \\
\text { No digui mentides 'no } \\
\text { diga mentiras' }\end{array}$ & $\begin{array}{l}\text { No expliqui l'última part } \\
\text { de la bistòria dient que } \\
\text { és barata 'No explique } \\
\text { la última parte de la } \\
\text { historia diciendo que es } \\
\text { barata' (suscitado por } \\
\text { D1, usando un verbo } \\
\text { dicendi) }\end{array}$ \\
\hline
\end{tabular}

Cuadro 3. Construcción de las voces. 


\subsubsection{Axiología}

La carga de valores positivos o negativos implícita en algunas palabras y en determinados contextos, connotan el discurso -e, indirectamente, al locutor que lo pronuncia- positiva o negativamente. Por eso es interesante analizar también este aspecto. El resultado obtenido es que D4 utiliza muchas palabras con axiología positiva referidas a la energía nuclear y al sufragio de otras energías que la nuclear posibilita ("barata", "solución", "funcionan", "permiten financiar"). En cambio, D1 utiliza palabras con axiología negativa referidas a la energía nuclear o a las empresas eléctricas relacionadas con ella ("trampa", "dictadura", "fallida", "no verdad", "no barata", "mentiras") y, cuando usa palabras con axiología positiva, lo hace en un contexto negativo ("privilegios"). D2, por su parte, no usa ningún tipo de axiología, ni positiva, ni negativa, lo que le resta efectividad.

\subsection{Retórica de la controversia}

La retórica se refiere a las estrategias discursivas empleadas por los participantes para conseguir la adhesión de la audiencia y a los aspectos ideológicos que intervienen en el intercambio discursivo. Es por ello que, en este apartado, analizaremos las diferentes formas argumentativas utilizadas por los debatientes, incluidas las figuras retóricas, para tener éxito en la controversia que protagonizan en un contexto de escena plural.

\subsubsection{Argumentos}

Partimos de la observación de que en la microcontroversia analizada hay tres tesis que son defendidas y criticadas, en tres momentos sucesivos, por los debatientes: D4 legitimado por su ethos como persona experta, que puede opinar con conocimiento de causa-, y D1 y D2, que recurren al pathos, desenmascarando "el mal" para intentar mover los sentimientos de la audiencia. En las tres fases de la controversia, correspondientes a cada una de las tesis defendidas, la argumentación de los locutores se caracteriza por su poca solidez, principalmente la de D1 y D2, que suelen contraargumentar con ataques a la persona. En cuanto a D4, muestra un discurso mas estructurado.

a) Tesis 1 [10:57-11:21]: La energía nUCleAr Nos proporciona [AHORA] ELECTRICIDAD BARATA (D4); rebatido por D1 y D2, con falacias "ad hominem" (D1 tilda a D4 de tramposo) y "de división" (D2 afirma que todos los usuarios subvencionan la energía nuclear, para termina aceptando que solo subvencionan parte de ella: los residuos). La contraargumentación de D4 utiliza la falacia "del equívoco" (D4 dice: "los residuos están financiados en la tarifa," ¡como si la tarifa no la pagaran los usuarios!), y, posteriormente, encuentra una fórmula mas convincente para concluir la polémica: la de que los usuarios pagan una parte ínfima de ella $(2 \mathrm{cms}$. de euro por $\mathrm{kw} / \mathrm{h}$ ), que es como no pagar nada. 
b) Tesis 2 (11.22-11.40): LA ENERGíA NUCLEAR YA FUE CARA DESDE EL PRINCIPIO (D1); rebatida por D4. D1 acusa a D4 de silenciar parte de la verdad (falacia "ad hominem"), e intenta relacionar "energía nuclear" y "privilegios corruptos" de la dictadura franquista, con la pretensión de desprestigiar a D4 y conmover a la audiencia. D1 utiliza la falacia "non sequitur", ya que, con lo que alega, no demuestra que las nucleares sean caras. Finalmente, D4 zanja el tema diciendo que la historia no sirve para solucionar un problema actual, que es lo que les acucia.

c) Tesis 3 (11.41-12.11): LA NUCLEAR SIRVE PARA SUBVENCIONAR ENERGías RENOVABLES, COMO LA EÓliCA (D4); protestada ad hominem per D2 y D1. D4, con enunciados mas matizados y conciliadores, afirma que la nuclear sirve para financiar en parte a las eólicas (falacia “de causa falsa”), lo que provoca una contraargumentación con falacias "de supresión de prueba" (D2) y "ad hominem" (D1). D4, una vez mas, acaba la polémica con una interpelación a D2, que es una falacia "de supresión de prueba": "Pero, hombre, haga usted los números en su totalidad".

\subsubsection{Figuras}

Se utilizan pocas figuras, y todas ellas para "vencer" al adversario. D4 se sirve de dos figuras "fuertes", la "tautología" ("Estamos en la situación que estamos y tenemos lo que tenemos"), para rechazar un tema que no le conviene y asentar lo que él ya ha esbozado, y la "corrección con reticencia" ("Pero, hombre, haga usted los números, haga usted los números en su totalidad"), con la que acusa de mentir a uno de sus adversarios. D1 ("Explique cómo se hizó la nuclear en este país, el régimen de dictadura, todos los privilegios que se dieron a las empresas eléctricas”) y D2 (“¿Cómo puede decir esto?") usan la "pregunta retórica" para acusar a D4 también de mentiroso. La "ejemplificación" (D2: "Porque nosotros estamos subvencionando los gastos de los residuos, por ejemplo" y D4: "En parte, su coste es el que permite financiar, por ejemplo, las eólicas que estan en operación”) no sirve para la comprensión de un hecho complejo, como sucede en el discurso didáctico, sino para desautorizar el discurso del oponente directo. Finalmente, las repeticiones transmiten desasosiego y contrariedad en D1 ("Escuche, explique toda la historia"; "no es verdad, esto no es verdad") y tranquilidad y seguridad, en D4 ("Una electricidad más barata que el resto de las energías, que el resto de las energías"; "y forma parte, y forma parte de la solución”; "haga usted los números, haga usted los números en, su totalidad”).

\subsection{Cámara, imágenes y emociones}

Aunque, como ya hemos dicho, no sea un objetivo fundamental en nuestro análisis de la controversia, queremos apuntar algunas observaciones sobre la relación “cámara-imágenes-emociones”. Por lo que respecta a la cámara, es interesante advertir sus movimientos: en la mayoría de ocasiones, enfoca, en un plano medio, a la persona que habla, pero en los momentos más agónicos, pasa del plano medio al plano de conjunto para mostrar la reacción de todos los debatientes. 
En cuanto a las imágenes de los debatientes, se observa que D1 y D2 gesticulan y se mueven en la silla de manera más expresiva y más nerviosa que D4, mientras que éste mantiene siempre una postura corporal y una expresividad relajada, que muestra una actitud un poco condescendiente hacia los interlocutores. En coherencia con estas actitudes, D1 y D2 hablan de manera crispada, rápida, precipitada, e interrumpen constantemente a D4. Todo ello produce un efecto de falta de control, de impaciencia, e incluso de irritación. El habla de D4, en cambio, es pausada, poco enfática, e incluso se ríe, en algunas ocasiones, desautorizando la intervención de alguno de sus oponentes.

En definitiva, los movimientos de la cámara captan imágenes que refuerzan lo que las palabras de los intervinientes sugieren a lo largo de la microcontroversia, ya que éstos exteriorizan su estado de ánimo con su cara y con sus gestos. Así, el enfoque subraya la positividad o la negatividad de sus emociones; la aparición, en algunos, de un grado de excitación extremado e inadecuado; y su alto o bajo nivel de dominio personal en una situación de lucha.

\section{Discusión y resultados}

La propuesta de Dascal (1995a, 1995b) ha resultado muy productiva para el análisis de la microcontroversia seleccionada. La observación de la dinámica de la discusión permite detectar los momentos más agónicos, dibujar el flujo de la argumentación y la contraargumentación, localizar los temas que provocan desacuerdo o contraposición y los que no merecen la atención de los oponentes, y visualizar el equilibrio o, en el caso que nos ocupa, el desequilibrio de poder entre los debatientes y la lucha por los turnos de habla, sobre todo a partir del análisis de los marcadores de inicio de turno.

El análisis de los componentes morfológico, pragmático y retórico ha permitido ver la relación entre las fases de la discusión y el encadenamiento semanticológico de las intervenciones, que incluye la selección de una modalidad enunciativa o de otra, la presencia de intensificadores, el uso transparente o diluido de las voces; la aparición de términos axiológicos, la construcción de las argumentaciones con los argumentos, los contraargumentos y las conclusiones correspondientes, y la utilización de las figuras retóricas.

Además, tal como es habitual en los debates televisivos, hemos visto que el conductor permite un enfrentamiento muy directo entre los debatientes, para poder responder a la vocación de espectáculo del medio y al propósito de convertir la sección del programa en un show de la palabra, al tiempo que mantiene un control casi absoluto sobre la dirección y el progreso del debate. En este sentido, los movimientos de la cámara y su insistencia en los planos medios captan también la exteriorización de las emociones de los debatientes a lo largo de la microcontroversia y corroboran lo que su discurso tan solo sugiere. 
Por todo ello, el análisis de la microcontroversia sobre el coste de la energía nuclear, del programa Els matins de TV3, nos ha permitido concretar que la fase de máxima confrontación de una controversia favorece la espectacularización de la palabra; sin embargo, su brevedad parece indicar que el medio televisivo solo puede soportar breves períodos de confrontación.

Los marcadores discursivos de inicio de turno -fundamentales en la lucha para conseguir y mantener la palabra- indican la escasa ritualización de la controversia y el poder de cada debatiente. El hecho de que la mayoría de marcadores sean 'modalizadores' -en detrimento de los 'estructurales' y los 'proposicionales'-, y expresen el desacuerdo y la contraposición, nos da una idea de hasta qué punto la controversia es agónica y contiene un alto grado de agresividad verbal.

La naturaleza de los enunciados varía siguiendo la evolución del debate, y en las fases de lucha -como en la microcontroversia analizada- se imponen los enunciados 'directivos' y 'expresivos', mientras que los 'asertivos' quedan en un segundo plano.

El tema de debate no es único: aunque gire en torno al coste de la energía nuclear, va cambiando rápidamente para dar paso a temas colaterales suscitados por los debatientes, porque los consideran mas útiles para la defensa de su punto de vista, que es lo que realmente les interesa.

Por lo que respecta a los participantes, se observan varios índices que sitúan a uno de los debatientes en una posición de superioridad en el dominio de la escena: la coherencia discursiva, la retención del turno de habla, el pragmatismo de su argumentación, la asertividad de sus enunciados, el dominio de la retórica y el gobierno de las emociones lo hacen posible.

Por su parte, los oponentes debilitan su argumentación al vehicular un mensaje de contenido emocional negativo (que alude a sucesos y acciones negativas: la dictadura, las trampas para privilegiar a ciertas empresas, la falsedad 'global' del discurso del debatiente contrincante...), al mostrar un alto grado de irritabilidad y crispación (enojo en las palabras, en la cara y en el gesto) y al contraargumentar con falacias, sobre todo ad hominem, para desacreditar al contrincante, lo que es una muestra de su debilidad argumentativa. En definitiva, frases del tipo "No diga mentiras, señor González", que profiere D1 como ataque frontal a la persona, no dan el efecto apetecido, y D4 sale airoso de la controversia. 


\section{REFERENCIAS BIBLIOGRÁFICAS}

Bradley, M. M. \& Lang, P. J. (1994). Measuring emotion: The self-assessment mannikin and the semantic differential. Journal of Behavior Therapy and Experimental Psycbiatry, 25(1), 49-59.

Compte, C. (2009). Limage en mouvement. La médiation du regard. París: Lavoisier.

Cros, A., Brunat, G. \& González, C. (2012). La construcció de la identitat dels participants. En M. Bassols (Coord.), La divulgació en els nous formats televisius (pp. 111-132). Bellaterra: Servei de Publicacions de la UAB.

Cuenca, M. J. \& Marín, M. J. (2006). Estratègies d'inici de torn del debat electoral. Journal of Catalan Studies, 20-47.

Charaudeau, P. (2008). L'argumentation dans une problématique d'influence. Argumentation et Analyse du Discours 1 [en línea]. Disponible en: http://aad.revues.org/index193. html.

Charaudeau, P. (2010). El análisis discursivo de los programas de televisión. Apuntes del seminario impartido al grupo Llengua i Mèdia de la UAB. Facultat de Ciències de la Comunicació de la UAB. Inédito

Dascal, M. (1995a). Epistemología, controversias y pragmática. ISEGORIA, 12, 8-43.

Dascal, M. (1995b). Observations sur la dynamique des contriverses. Cabiers de Linguistique Française, 17, 99-121.

Ducrot, O. (1984). Esquisse d'une théorie polyphonique de l'énonciation. En O. Ducrot (Ed.), Le dire et le dit (pp. 171-233). París: Editorial de Minuit.

Hutchby, I. (1996). Confrontation talk. Arguments asymmetries and powver in talk radio. Nueva Jersey: Lawrence Erlbaum.

Hutchby, I. (2006). Media talk. Conversation analysis and the study of broadcasting. Glasgow: Open University Press.

Kress, G. \& Van Leeuwen, T. (2001). Multimodal discourse. The modes and media of contemporary communication. Londres: Arnold.

Perelman, C. \& Olbrechts-Titeca, L. (1970). Traité de l'argumentation. La nouvelle rhétorique, Brussel-les: Éditions de l'Université de Bruxelles. París: PUF.

Shiffrin, D. (1994). Approaches to discourse. Oxford: Blackwell.

Van Eemeren, F. H., Grootendorst, R., Jackson, S. \& Jacobs, S. (1993). Reconstructing argumentative discourse. Alabama: The University of Alabama Press. 
Walton, D. (1996). Argument structure. A pragmatic theory. Toronto: University of Toronto Press.

Weston, A. (1987). A rulebook for arguments. Cambridge: Avatar Books. 